\title{
CRISIS TYPOLOGIES REVISITED: AN INTERDISCIPLINARY APPROACH
}

Björck, A.

For effective crisis management and communication, a decision maker has to understand the causes and nature of a crisis and how it influences stakeholder perceptions. Identifying an organization's vulnerabilities is essential for crisis prevention but practitioners often lack the ability to define crisis scenarios, especially the worst-case ones. A crisis typology is a structured approach to analyze crisis situations and to introduce measures for crisis prevention and containment. This paper aims to review recent literature on crisis classifications and to discuss their application. Because a single typology cannot capture the complexity and the interdisciplinary nature of a crisis, four relevant typologies from different disciplines are compared. Their combined application in an interdisciplinary framework is suggested. The paper discusses the need for typologies that reflect the cultural and contextual dimensions. Conclusions concerning the limitations and directions for further research are drawn.

Keywords: Crisis management; strategic crisis communication; interdisciplinary approach; intercultural analysis; contextual influence

JEL Classification: D81, M16

\section{Introduction}

A crisis communication practitioner cannot be blamed for missing real crisis examples of considerable scope in recent years: terror attacks (2001-today), catastrophic natural disasters (Nepal earthquake 2014 or Indian ocean tsunami catastrophe 2004), accidents of a global scope (Fukushima nuclear plant 2014 or the BP oil spill in the Gulf of Mexico 2010), ongoing international organizational crises like the Volkswagen emissions scandal or the FIFA corruption crisis. It seems the societal and organizational vulnerability has risen with growing globalization and penetration of new technological advancements. Not only are we confronted with crises more often, but their scope, complexity and ambiguity pose new and greater challenges to the way we think and organize. Crisis management and communication is a task every manager and board member, not just public relations professionals, has to understand and perform in order to guard an organization's image and reputation (Forbes Insight, 2016). Crisis management and communication require strategic thinking, and a critical important first step is the proper identification of a crisis situation (Burnett, 1998). This is the area where problems usually begin.

There is no universally accepted definition of a crisis (Coombs, 2012). The word crisis has its roots in the Greek "krisis", meaning breach and discontinuity. Today the term has found inflationary use and defines any change of daily routines without consideration of scope, severity and outcome. In this paper, a definition according to Fearn-Banks (2009) is used: a crisis is "a major occurrence with a potentially negative outcome affecting an organization, company, or industry, as well as publics, services or good name. It interrupts normal business transactions and can sometimes threaten the existence of the organization." 
The management and resolution of a crisis is one of the most difficult strategic issues decision makers face because of conditions of high uncertainty, time pressure, and limited control (Burnett, 1998). The timing of occurrence, duration, path of development and outcome are seldom known (Merten, 2008). The effectiveness of crisis management and communication is not precisely assessable in advance because of the many unknown variables like stakeholder perceptions and the imperfect information about the cause (Merten, 2005). Crises can have many faces and variable outcomes (negative, positive or even catastrophic) and thus the preparation encompasses the definition of crisis scenarios of different probability of occurrence (Mast, 2008). It can be concluded that a crisis starts with a trigger event, can change its nature over time and can have uncertain outcomes, shaped by the interplay of changing stakeholder perceptions (for example media pressure), organizational crisis management and communicative efforts as well as how fast the real trigger and cause are revealed.

Keeping so much uncertainty and complexity in mind, the practical question arises: can you prepare for a crisis? A perfect preparation is an illusion. The reality shows that the more severe crises a practitioner has encountered, the better crisis manager he or she is, similar to the proverb "What doesn't break you makes you stronger." A pragmatic approach for crisis preparation consists first of the analysis and classification of experienced and observed crises, and the associated management and communication mistakes or successes. Additionally, for an organization it is important to constantly work on its general resilience, "antifragility" (Taleb, 2012). This article aims to make a contribution to structuring the first step.

Only by understanding a crisis situation can a manager select the appropriate mode of action and communication (Coombs, 1998). A typology is valuable because it simplifies and structures complexity, helps to organize the collection of information, provides diagnostic insights (Burnett, 1998) and is a first step to contain a crisis (Gundel, 2005). It is an important starting point as it helps constructing crisis scenarios, thereby streamlining possible actions and outcomes. It is not surprising that "a plethora of crisis typologies" (Coombs and Holladay, 2002) exists. But the continuous absence of a sufficient typology of crisis and disasters is exceptionally painful (Quarantelli, 2001). A further problem with crisis typologies is that they always reflect our current knowledge and estimation of crisis events as we only can classify what we know (Gundel, 2005).

This paper aims to review recent literature on crisis situation classifications and to discuss their practical applicability. After an overview of process-oriented and one-dimensional classifications, four two-dimensional typologies from different disciplines are presented: crisis and disaster management, mathematics and statistics, sociology and psychology, public relations and communication theories. These typologies deliver valuable insights on separate crisis characteristics: cause, impact, predictability, and stakeholder perceptions. In order to draw a complete crisis picture, the combination of the typologies into a framework for crisis analysis is suggested. Missing typologies related to culture and context are discussed and possible dimensions are presented. The paper concludes with directions for further research. 


\section{Theoretical Background}

\subsection{A Crisis Typology}

There are two main perspectives on crisis typologies - the time perspective and the content perspective (Thiessen, 2008). The time perspective describes a crisis as a process with three or more main phases. According to Coombs (2012), three phases describe a crisis event: pre-crisis, crisis and post-crisis. The pre-crisis phase covers the time before the effective crisis event and the preparation measures, including environmental scanning and issue management, training of spokespeople, crisis team and communication with stakeholders about possible risks. A trigger event and the damage ensued characterize the crisis phase or the "acute" phase when the organization acts and communicates to resolve the dangerous situation. Post-crisis is the phase of learning and resolution. A major shortcoming of the process models is the difficulty to exactly classify when a phase starts and when it ends (Thiessen, 2008).

According to the content perspective, there are one-dimensional or multidimensional typologies. The oldest and simplest typology distinguishes between intentional man-made crises and natural external causes (Rosenthal and Kouzmin, 1993). Another widely used typology builds on the previous and classifies crises as sudden (unexpected, happen overnight) or smoldering (slowly developing, structural) (James and Wooten, 2005). Examples for sudden crises are natural disasters, terror attacks, explosions, technological incidents. Smoldering crises are usually triggered by management mistakes, quality problems, whistle-blowing or consumer criticism and activism. On the one hand, one-dimensional typologies are easy to understand and apply, but cannot depict the typical complexity of crises. On the other hand, multidimensional typologies are too complex and seldom practicable.

\subsection{Two-Dimensional Typologies}

According to Gundel (2005), a classification of crises is "the first step to keep them under control" and allows for analysis and planning of crisis management actions. He defines four conditions for a good typology: 1) mutually exclusive classes, 2) exhaustive, covering also future events, 3) practicable, i.e. covering measures of prevention and 4) pragmatic thus manageable. In recent literature, two-dimensional typologies try to compensate for the disadvantages of one- and multidimensional classifications while addressing the four conditions. Four relevant typologies will be shortly presented. They provide guidelines for risk and crisis management as well as for assessment of the crisis cause and impact (Gundel, 2005 and Taleb, 2007) or for crisis communication strategies as well as evaluation of stakeholders' perceptions (Weiner, 1995 and Coombs et al., 1995).

\section{Predictability-Influence Matrix}

The first typology, developed by Gundel (2005), is a four-area matrix based on two variables: predictability and influence (Figure 1). Predictability is defined as the extent to which the particular kind of crisis can be known and highly probable based on previous experiences. Predictable events are transport accidents, water shortage in some regions, technical risks, issues likely to lead to social unrest etc. The influence dimension encompasses known and executable measures to address the causes of a crisis. The author distinguishes 
among four types of crisis: conventional, unexpected, intractable, and fundamental. In the case of conventional crises like ferry accidents or explosions in a chemical plant, the occurrence of the event is known and probable, thus predictable, and easy to prevent with proper quality controls and planning. Unexpected crises are manageable but difficult to predict. An emergency response can combat the crisis successfully but its surprising occurrence can hinder the solution. This crisis type is illustrated by the tunnel blaze 2000 in Kaprun, Austria, when a railway that was considered fire-proof burnt down and killed 151 people because of false expert assumptions before the accident. The third type is the intractable crisis that can have precedents in the past and be expected but countermeasures are difficult because of the complexity of systems or conflicts of interest surrounding. Examples include the accident at Fukushima nuclear plant 2014 after the devastating earthquake and tsunami. Fundamental crises are unpredictable and difficult to influence, thus the most dangerous type. Events falling into this category are the terrorist attacks on 9/11, 2001 or a future crisis resulting from the application of gene technology.

Figure 1 | Predictability-Influence Matrix

\section{PREDICTABLE \\ HARD \\ EASY

\begin{tabular}{l|l|}
$\begin{array}{l}\text { Unexpected crises (2) } \\
\text { Measures: Emergency } \\
\text { response }\end{array}$ & $\begin{array}{l}\text { Fundamental crises (4) } \\
\text { Measures: no preparation } \\
\text { possible }\end{array}$ \\
\hline $\begin{array}{l}\text { Conventional crises (1) } \\
\text { Measures: quality control } \\
\text { and crisis planning }\end{array}$ & $\begin{array}{l}\text { Intractable crises (2) } \\
\text { Measures: Reduce } \\
\text { complexity and conflict } \\
\text { of interest }\end{array}$ \\
\hline
\end{tabular}

EASY
HARD
INFLUENCABLE

Source: Gundel (2005)

\section{Probability-Impact-Matrix}

The second typology, the Probability-Impact-Matrix has its roots in financial mathematics and statistics and is often used in risk assessment. Risk events are classified according to two dimensions: probability of occurrence and payoff / impact. In the context of the last financial crisis, the risk assessment received a new interpretation and meaning through the work of Nassim Taleb. His analysis of risk events questioned the overreliance on statistics and addressed the illusion that complex models can predict the future. According to Taleb (2007), the human mind suffers from three limitations when it comes to interpretation of past experiences: 1) "the illusion of understanding, how people think they know what is going on in a more complex and random world than they realize", 2) "the retrospective 
distortion, or history seem clearer in a history book than in an empirical reality" and 3) "the overvaluation of factual information, or the handicap of authoritative and learned people."

People regularly dismiss improbable events as they seek arguments to justify their own prognoses than to falsify them. People dismiss the "silent evidence" (Taleb, 2007), thus the silent signals and random signs for these unexpected events. They prefer to concentrate on familiar information sources and a few known scenarios. When the unexpected and unthinkable happens, they try to rationalize ex-post. These unexpected and unthinkable events happen more often than we realize - Taleb calls them "black swans". Figure 2 illustrates a four-field-matrix with "Black swans" positioned in the so-called "Fourth Quadrant".

Figure 2 | Probability-Impact-Matrix

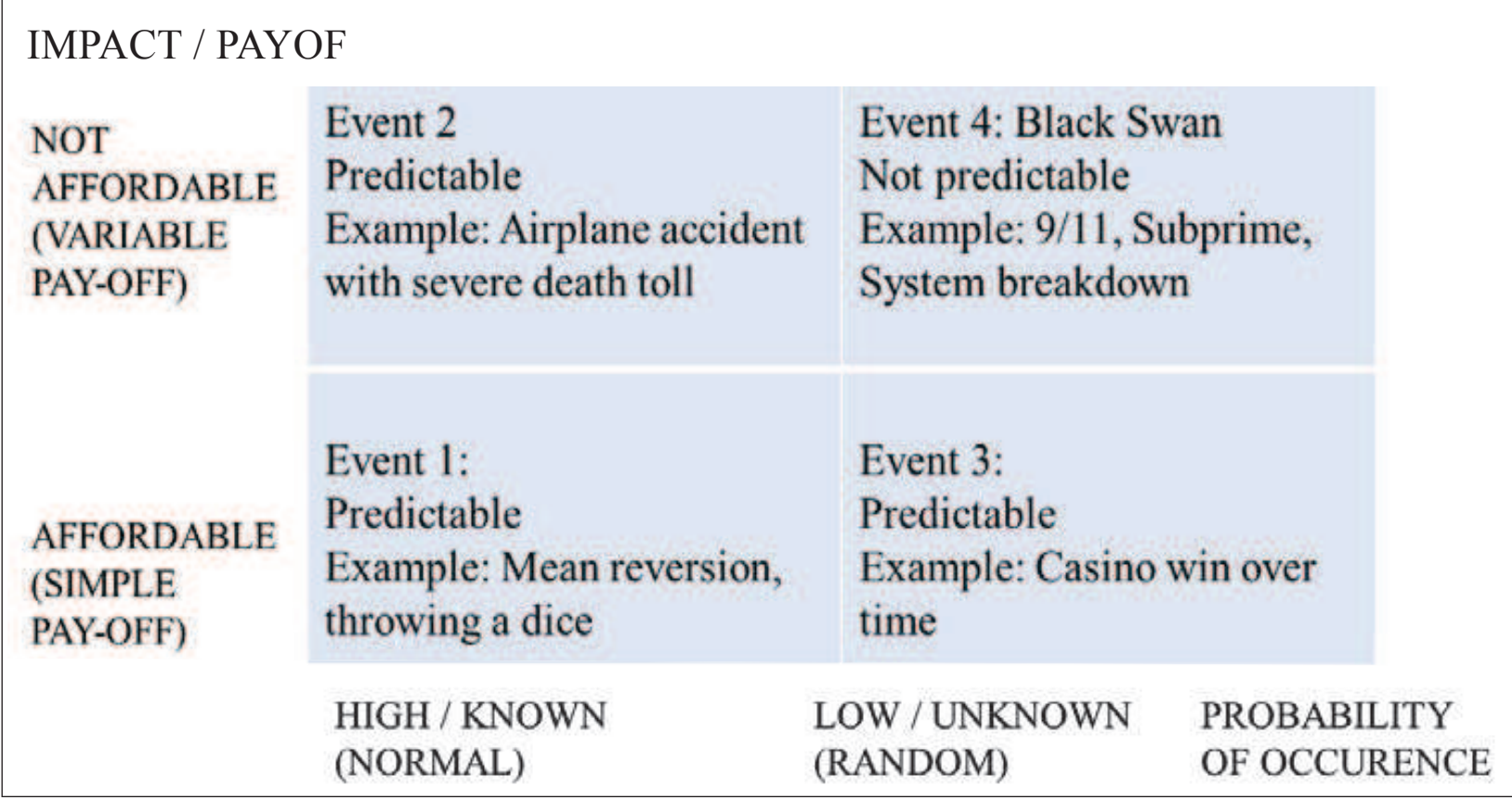

Source: Taleb $(2004,2007)$

Black swans (Taleb, 2004) lie behind the realm of normal expectations and are thus unpredictable (the Subprime Crisis 2007) and can have extreme effects (The Fall of the Iron Curtain 1989). Furthermore, the unexpectedness creates the very conditions for their occurrence (9/11) and they can be easy explained ex-post (spreading of the Internet).

\section{Locus-Controllability Matrix and the Responsibility Continuum}

The third and fourth typologies are based on two theories that explain how the organizational crisis response influences the perception of stakeholders: Weiner's attribution theory (WAT) and the Situational Crisis Communication Theory (SCCT). WAT has its roots in sociology and psychology and attempts to explain how people make sense of events; SCCT builds upon it and adapts it for the needs of crisis communication (Coombs, 2012).

According to WAT, an event has an impact on peoples' perceptions: They interpret the cause of the event according to existing information from the media, organizational 
response, experts or other sources and attribute responsibility. Two dimensions for classifying events are being used: locus (is the cause located inside and outside of the organization) and controllability (was the cause under the company's control) (Figure 3).

Figure 3 | Locus-Controllability Matrix

\begin{tabular}{|l|l|l|}
\hline $\begin{array}{l}\text { LOCUS } \\
\text { OF CAUSE }\end{array}$ & $\begin{array}{l}\text { Example: } \\
\text { Employee sabotage }\end{array}$ & $\begin{array}{l}\text { Example: } \\
\text { Neglected maintenance } \\
\text { Stakeholder attitude: } \\
\text { Negative, blame }\end{array}$ \\
\hline OUTSIDE & $\begin{array}{l}\text { Example: } \\
\text { Terrorist sabotage } \\
\text { Stakeholder attitude: } \\
\text { Positive, sympathy }\end{array}$ & $\begin{array}{l}\text { Fample: } \\
\text { Failure to protect against } \\
\text { a common external threat }\end{array}$ \\
\hline $\begin{array}{l}\text { NOT UNDER } \\
\text { CONTROL }\end{array}$ & $\begin{array}{l}\text { UNDER CONTROL } \\
\text { CONT CAUSE }\end{array}$ \\
\hline
\end{tabular}

Source: Weiner's Attribution Theory (McDonald et al., 2010, Weiner, 1995)

The interpretation of the locus and controllability results in a judgement that leads to emotions and behavioral intentions. Figure 3 shows examples of negative events for every matrix field. When a crisis is perceived to have an outside cause not under the control of the organization then the empirical evidence shows a positive attitude, even sympathy by stakeholders. The audiences judge that the organization was to blame for the crisis in case of an internal cause under the organization's control.

The SCCT translates the attribution theory into the field of crisis communication, and connects for the first time the crisis situation with crisis response strategies. The theory builds upon two main propositions similar to WAT: First, stakeholders perceive crises differently. Second, their perceptions are influenced by the attributed responsibility for the crisis event.

A crisis communicator starts with identifying the crisis type and how it affects stakeholders before choosing a communication strategy. The greater the crisis responsibility attributed, the more accommodative the communication strategy must be. Weaker perceptions of responsibility require more defensive communication strategies (Coombs, 1998). The SCCT develops a process model in two steps. In the first step, the crisis situation is identified and classified according to the responsibility attributed. For this purpose, Coombs develops a master list of crisis types and groups them into three clusters based on the level of crisis responsibility. These are positioned on a high-low responsibility continuum (Utz et. al., 2013, 42):

- intentional crisis - highest responsibility attributed, because of intended mistakes and thus preventable in the eyes of the public. An example is the ongoing 
Volkswagen gas manipulation scandal where the application of test-cheating software with the knowledge of management caused one of the biggest reputation crises of recent years.

- accidental crises - higher responsibly attributed, the organization is confronted with a crisis because of unintentional mistakes, not preventable because unconscious. In 2015, a pilot intentionally brought down a German Wings plane with 150 persons onboard over the French Alps. But German Wings and Lufthansa weren't confronted with the highest responsibility, because the pilot hid his psychological problems from his employer.

- $\quad$ victim crises - low responsibility attributed, organizations and stakeholders are both victims and the crisis is perceived as not preventable. An example is the recent terrorist attacks in Paris and Brussels 2015-2016.

In a second step, further factors are considered which can intensify the attributed responsibility. Two factors have been empirically proven - the previous crisis history and the existing reputation (Coombs and Holladay, 2001). The more severe intentional crises the organization has experienced and the more negative the existing reputation, the higher the responsibility attributed. At the same time, a highly positive reputation can shield the company and reduce the attributed responsibility (Coombs and Holladay, 2006). The theory states also that with the use of communication strategies adapted to the situation, the attribution of responsibility and the behavior of stakeholders can be influenced. Further, a set of crisis response strategies for every crisis type is suggested.

\section{Discussion}

\subsection{A Need for an Interdisciplinary Framework}

All four typologies deliver valuable but limited insights for crisis management and communication professionals. The predictability-influence matrix and the audience based typologies allow for generalization and the dimensions applied are mutually exclusive. The works of Taleb $(2004,2007)$ introduce a new perspective on managerial risk and crisis thinking. But the knowledge from every typology is isolated in the logic of the rooted discipline. On the one hand, the predictability-influence matrix, based in crisis and disaster management, defines implications for crisis prevention, emergency response preparedness and other organizational countermeasures. On the other hand, the audience based typologies, rooted in sociology and psychology, focus only on suitable communication response considering stakeholder perceptions, emotions and behavior.

Realistic and thus usable crisis scenarios depict not separate elements but a sum of substantial crisis determinants: cause, impact, stakeholder perceptions as well as suitable crisis management and communication actions. The insights from the different and relevant typologies need to be combined in a framework (See Figure 4). Or as Giplin and Murphey (2006) point out, the complexity of a crisis requires an interdisciplinary approach, i.e. drawing knowledge from various disciplines. 
Figure 4 | Interdisciplinary approach for framing crisis situations with implications for crisis management and communication

\begin{tabular}{|c|c|}
\hline $\begin{array}{c}\text { PREDICTABILITY- } \\
\text { INFLUENCE MATRIX } \\
\text { (Gundel, 2005) }\end{array}$ & $\begin{array}{c}\text { LOCUS- } \\
\text { CONTROLLABILITY } \\
\text { MATRIX } \\
\text { (Weiner, 1995) }\end{array}$ \\
\hline MROBABILITY-IMPACT \\
(Taleb, 2007)
\end{tabular}

Table 1 | Comparison of the crisis typologies involved in the interdisciplinary framework

\begin{tabular}{|l|l|l|l|l|}
\hline Author & \multicolumn{1}{|c|}{ Gundel (2005) } & \multicolumn{1}{|c|}{ Taleb (2007) } & \multicolumn{1}{|c|}{ Weiner (1995) } & Coombs et. al (1995) \\
\hline Dimension 1 & $\begin{array}{l}\text { Predictability } \\
\text { (Crisis is known) }\end{array}$ & $\begin{array}{l}\text { Probability of } \\
\text { occurrence }\end{array}$ & $\begin{array}{l}\text { Locus of cause } \\
\text { (inside or outside) }\end{array}$ & $\begin{array}{l}\text { Locus of cause } \\
\text { (Inside, outside) }\end{array}$ \\
\hline Dimension 2 & $\begin{array}{l}\text { Influence possibili- } \\
\text { ties on the cause }\end{array}$ & Impact / Payoff & $\begin{array}{l}\text { Controllability of } \\
\text { cause }\end{array}$ & Intent \\
\hline Discipline & $\begin{array}{l}\text { Crisis and disaster } \\
\text { management }\end{array}$ & $\begin{array}{l}\text { Mathematics } \\
\text { and statistics }\end{array}$ & $\begin{array}{l}\text { Sociology and } \\
\text { psychology }\end{array}$ & Crisis communication \\
\hline Perspective & $\begin{array}{l}\text { Crisis and disaster } \\
\text { manager }\end{array}$ & $\begin{array}{l}\text { Risk and crisis } \\
\text { manager }\end{array}$ & $\begin{array}{l}\text { General audience } \\
\text { and stakeholders }\end{array}$ & $\begin{array}{l}\text { Stakeholders and } \\
\text { crisis communicator }\end{array}$ \\
\hline $\begin{array}{l}\text { Implications } \\
\text { for business } \\
\text { practice }\end{array}$ & $\begin{array}{l}\text { Risk and crisis } \\
\text { management } \\
\text { measures, } \\
\text { regulation }\end{array}$ & $\begin{array}{l}\text { Focus on worst } \\
\text { scenario (black } \\
\text { swan), } \\
\text { general } \\
\text { resilience of } \\
\text { organizations }\end{array}$ & $\begin{array}{l}\text { Attributed respon- } \\
\text { sibility by stake- } \\
\text { holders, emotions } \\
\text { and behaviors }\end{array}$ & $\begin{array}{l}\text { Attributed res- } \\
\text { ponsibility by stake- } \\
\text { holders, emotions } \\
\text { and behaviors, } \\
\text { context factors, } \\
\text { crisis communication } \\
\text { strategies }\end{array}$ \\
\hline $\begin{array}{l}\text { Application } \\
\text { in crisis } \\
\text { phase }\end{array}$ & $\begin{array}{l}\text { Pre-Crisis and Crisis } \\
\text { Phase }\end{array}$ & $\begin{array}{l}\text { Pre-Crisis and } \\
\text { Post-Crisis }\end{array}$ & $\begin{array}{l}\text { Pre-Crisis and Crisis } \\
\text { Phase }\end{array}$ & $\begin{array}{l}\text { Pre-Crisis and Crisis } \\
\text { Phase }\end{array}$ \\
\hline
\end{tabular}


An interdisciplinary approach allows a decision maker to assess crisis situations from different angles, to apply scenario planning and to formulate strategic alternatives. The variety of perspectives correspond better to the background and understanding of crisis team members, normally representing different positions and functions in the organization. Their views and interpretations are more easily integrated and a common crisis knowledge is built. The typology framework not only structures possible situations but also points to appropriate management and communication measures that can be introduced before, during and after a crisis. Table 1 summarizes the dimensions, the different perspectives and the implications for business practice.

\subsection{Framework's Drawbacks}

The presented interdisciplinary approach still has some significant drawbacks, based on the current state of research and empirical evidence. First, it does not consider a development path typology: how a crisis can evolve over time under the influence of different factors, like stakeholder perceptions. Second, a classification tends often to be highly analytical and difficult to clearly attribute to a certain crisis cluster (Thiessen, 2011) or it requires data analysis and understanding of statistics that is often not the focus of crisis managers and communicators. Third, the audience based typologies like SCCT still need an empirical operationalization. According to Schwarz (2008) it might be problematic to assume "that each crisis type generates specific and predictable levels of crisis responsibility - attributions of organizational responsibility for the crisis." Because there are (a) various crisis types (e.g., age discrimination, consumer boycott or protest, chemical spill, layoffs, product tampering, etc.); (b) continuous and rapid emergences of new ones; and (c) possible variations within each crisis type, it may be more meaningful to unveil some generic underlying patterns of stakeholders' evaluation process in organizational crisis than to produce a probably non exhaustive list that matches each crisis type to a causal attribution (Lee, 2005). Many of the empirical studies performed were using students as respondents and not experienced crisis communication professionals and business professionals (Coombs and Holladay, 2002).

\subsection{Missing Typologies on Culture and Context}

Last but not least, important influencing factors for crisis management and communication like culture and context adaptability are not reflected in any typology. International corporate crises like the ongoing Volkswagen emission scandal pose an ever increasing challenge for crisis management and communication in a multicultural environment. Coombs (2012) acknowledges that crisis communication becomes increasingly complex as it crosses borders and shares messages with multiple countries and cultures. Surprisingly, crisis communication theory seems to lack cultural contextualization (Lee, 2005) and crisis management and communication research lack a long-standing tradition for including an intercultural perspective (Frandsen and Johansen, 2010). A comprehensive crisis classification along cultural aspects is still absent in academic research, although the culture is recognized by SCCT as an important factor of stakeholder perceptions (Coombs, 2012).

The perception of and reaction to certain crises types varies across stakeholders of different nationality and culture. While expanding its business abroad, an organization has 
to deal simultaneously with international/global stakeholders and local/nationwide ones that are more or less multicultural. A major strategic issue in every internationalization effort is the global standardization or local adaptation of the supporting and value creating activities, including marketing and communication (Hill, 2014). Historical research stresses the necessity to adapt communications in terms of language, content, non-verbal communication, media consumption and technology use, visual features, rhetoric and argumentation strategies (Ravazzani, 2016). The adoption of global values (for example global employer branding) and a singular corporate language are mentioned as effective instruments to overcome cultural differences and support standardization efforts (Hill, 2014). The question of which crisis type requires standardized crisis communication and which one needs idiosyncratic adaptation to different cultures remains unanswered. According Ravazzani (2016) some crisis types can be more pertinent culture-wise and require cultural adaptation of the internal crisis communication. These include organizational changes like reorganization and restructuring or emergency situations that put employees at risk, such as terrorism and natural disasters.

Comparing 43 European countries, Verhoeven et al. (2014) found significant differences in the way communication professionals assess a crisis event, in the importance of different crisis types and the communication strategies employed. Crisis situations were "differentiated by region and type of organization" (Verhoeven et al., 2014). The differences confirmed how important the economic and cultural context of organizations is for the genesis and labelling of a situation as a crisis. For example, professionals in Southern and Eastern Europe encountered a crisis more often than professionals in Western and Northern Europe. Financial and economic crises were the dominating crisis types in Southern and Eastern Europe, while management and leadership crises occurred more often in Western and Northern Europe.

\section{Conclusion and Directions for Future Research}

In addition to overcoming the disadvantages of every typology, future research should focus on exploring the challenges for the practical application of an interdisciplinary framework and its further development. The following three directions for development have been identified in this paper.

First, the changing nature of a crisis over time is a major problem. A crisis cause constitutes a focal point for many typologies but in most cases it is not known from the onset. The crisis type can change over time, influenced by changing stakeholder perception (like media pressure) and organizational crisis management and communication (like mistakes). Furthermore, the velocity and scope of a crisis can rapidly change with the help of new communication technologies and social media: timing has always been a critical factor for solving a crisis. An interview faux pas in a local radio station can evolve into a global reputation problem in a matter of hours.

Second, crises are becoming increasingly international and intercultural events, with growing globalization and the spreading of new communication technologies. The crisis manager and communicator acts on a global scene and navigates between the need to adapt the message to intercultural stakeholders or follow a standardized approach. Recent studies suggest that there are crisis situations requiring standardization and others adaptation of the communication strategy and main message. 
Third, crises are highly contextual events, influenced by a unique combination of environmental, historical, economic and cultural factors. The research literature is still dominated by Western contexts (US and Western Europe) and empirical studies and applications in other regions (Eastern Europe, Asia, Latin America, Middle East or Africa) are less common.

This manuscript seeks to fill a gap in the literature on crisis typologies concerning the interdisciplinary and complex nature of a crisis event. The aim is to suggest a framework that allows for analysis of crises situations and the introduction of appropriate management and communication measures. The framework can support a decision maker in the preparation, containment and learning from a crisis. Further research is needed to overcome the disadvantages of the included typologies, to discover and validate synergies as well as to complete the framework with new findings on the development path of a crisis, the integration of the cultural dimension and context specific aspects. The application on past crisis cases and in crisis preparation workshops with practitioners would facilitate valid and practicable guidelines for crisis management and communication.

\section{References}

Burnett, J. J. (1998). A Strategic Approach to Managing Crisis. Public Relations Review, 24(4), 475-488.

Coombs, T. (1995). Choosing the right words - the development of guidelines for the selection of the "Appropriate" Crisis-Response Strategies. Management Communication Quarterly, 8(4), 447-476.

Coombs, T. (1998). An Analytic Framework for Crisis Situations: Better Responses from a Better Understanding of the Situation. Journal of Public Relations Research, 10(3), 177-191.

Coombs, T. (2012). Crisis Communication and its allied fields. In Coombs T., \& Holladay S. (Eds.), The Handbook of Crisis Communications (pp. 54-65). Blackwell Publishing.

Coombs, T., \& Holladay, S. (2001). An Extended Examination of the Crisis Situations: A Fusion of the Relational Management and Symbolic Approaches. Journal of Public Relations Research, 13(4), 321-340.

Coombs, T., \& Holladay, S. (2002). Helping Crisis Managers to protect reputational assets. Management Communication Quarterly, 16(2), 165-186.

Coombs, T., \& Holladay, S. (2006). Unpacking the halo effect: reputation and crisis management. Journal of Communication Management, 10(2), 123-137.

De Wolf, D., \& Mejri, M. (2013). Crisis communication failures: The BP Case story, International Journal of Advances in Management and Economics, 2(2), 48-56.

Fearn-Banks, K. (2009). Crisis communications: A casebook approach. New York: Routledge.

Frandsen, F., \& Johansen, W. (2010). Corporate crisis communication across cultures. In Trosborg, A. (Ed.). Pragmatics Across Languages and Cultures (pp. 543-569). Berlin: Mouton De Gruyter.

Forbes Insights, in cooperation with Deloitte Touche Tohmatsu (2016). A Crisis of Confidence Global study of 300 board members. Retrieved July 4, 2016 from http://www.deloitte.com/ acrisisofconfidence. 
Giplin, D., \& Murphy, P. (2006). Reframing crisis management through complexity. In Botan C. H., \& Hazelton V. (Ed.), Public relations theory II (pp. 375-392). Routledge.

Gundel, S. (2005). Towards a New Typology of Crises. Journal of Contingencies and Crisis Management, 13(3), 106-115.

Hill, R. (2014). International Business - Competing in the Global Market Place. New York: Mcgraw-Hill.

James, E. H., \& Wooten, L. P. (2005). Leadership as (un)usual: How to display competence in times of crisis. Organizational Dynamics, 34(2), 141-152.

Lee, B. K. (2005). Crisis, culture, community. In Kalbfleisch, P. J. (Ed.), Communication Yearbook, Vol. 29 (pp. 275-309). Mahwah, NJ: Erlbaum.

Mast, C. (2008). Nach der Krise ist vor der Krise - Beschleunigung der Krisenkommunikation. In Nolting, T., \& Thiessen, A. (Eds.), Krisenmanagement in der Mediengesellschaft Potenziale und Perspektiven der Krisenkommunikation (pp. 83-98). Wiesbaden.

McDonald, L. M., Sparks, B., \& Glendon, A. I. (2010). Stakeholder reactions to company crisis communication and causes. Public Relations Review, 36(3), 263-271.

Merten, K. (2005). Begriff, Struktur und Funktion von Krisen. In Neujahr, E. (Ed.), SOS-Krise souverän - orientiert - sicher: PR in schwierigen Zeiten (pp. 17-34). München.

Merten, K. (2008). Krise und Krisenkommunikation: Von der Ausnahme zur Regel? In Nolting, T., \& Thiessen, A. (Eds.), Krisenmanagement in der Mediengesellschaft - Potenziale und Perspektiven der Krisenkommunikation (pp. 83-98). Wiesbaden.

Quarantelli, E. L. (2001). Another Selective Look at Future Social Crisis: Some Aspects of Which We Can Already See in the Present. Journal of Contingencies and Crisis Management, 9(4), 233-237.

Ravazzani, S. (2016). Exploring internal crisis communication in multicultural environments: A study among Danish Managers. Corporate Communications: An International Journal, 21(1), 73-88.

Rosenthal, U., \& Kouzmin, A. (1993). Globalizing an Agenda for Contingencies and Crisis Management. Journal of Contingencies and Crisis Management, 1(1), 1-12.

Schwarz, A. (2008). Covariation-Based Causal Attributions during Organizational Crises: Suggestions for extending Situational Crisis Communication Theory (SCCT). International Journal of Strategic Communication, 2(1), 31-53.

Taleb, N. (2004). Learn to expect the unexpected. The New York Times. Retrieved July 4, 2016 from http://www.nytimes.com/.

Taleb, N. (2007). The Black Swan. London: Penguin.

Taleb, N. (2012). Antifragile: Things that Gain from Disorder. New York: Random House.

Thiessen, A. (2011). Organisationskommunikation in Krisen - Reputationsmanagement durch situtative, integrierte und strategische Krisenkommunikation. VS Verlag für Sozialwissenschaften.

Utz, S., Schultz, F., \& Glocka, S. (2013). Crisis communication online: How medium, crisis type and emotions affected public reactions in the Fukushima Daiichi nuclear disaster. Public Relations Review, 39(1), 40-46. 
Verhoeven, P., Tench, R., Zerfass, A., Moreno, A., \& Vercic, D. (2014). Crisis? What crisis? How European professionals handle crises and crisis communication. Public Relations Review, 40(1), 107-109.

Weiner, B. (1986). An attribution theory of motivation and emotion. New York: Springer-Verlag.

Weiner, B. (1995). Judgements of responsibility. New York: The Guildford Press.

\section{Dr. oec. HSG Albena Björck}

Senior Lecturer and Head of Corporate Education

Department of International Business

Zurich University of Applied Sciences, School of Management and Law

Stadthausstrasse 14, 8401 Winterthur, Switzerland

albena.bjoerck@zhaw.ch, bjoe@zhaw.ch 